\title{
GOYA Y SU SINTOMATOLOGÍA MICCIONAL DE BURDEOS, 1825
}

Juan José Gómiz León.

Servicio y Cátedra de Urología. Hospital Clínico Universitario San Carlos. Madrid. España.

Resumen.- El célebre pintor don Francisco de Goya y Lucientes (1746-1828) padeció a lo largo de su vida una o varias enfermedades cuya naturaleza no ha sido determinada con seguridad. Los episodios mórbidos, parcialmente documentados, correspondientes a los años 1792-1793, acontecidos en Sevilla y Cádiz; 1819, en Madrid, y 1825, en Burdeos, pudieran estar relacionados entre sí. En éste último, los signos y síntomas urológicos que el ilustre enfermó presentó sí han quedado acreditados.

El objetivo del presente trabajo es proponer, recurriendo al material que no es otro que el "Diplomatario de Goya", con las cartas y documentos que hasta la fecha han sido coleccionados y dados a conocer, pretendiendo observar un método inductivo-deductivo en su estudio e interpretación e interrelacionando estas valiosas fuentes tanto con los conocimientos médicos de la época como los contemporáneos, particularmente en lo que a sus aspectos urológicos se refiere, y revisando la bibliografía disponible al respecto, con las naturales reservas de un pronunciamiento diagnóstico retrospectivo que por tanto, por sus inherentes características, no puede ser de total certidumbre, la hipótesis de la tabes dorsal neurosifilitica como responsable de los trastornos miccionales que se le presentaron en Burdeos en la primavera de 1825.

Igualmente, y de manera complementaria, se incluye un breve repaso de algunas de las circunstancias y personajes que rodearon al artista en Francia para ayudar a incardinar y comprender mejor la personalidad de Goya, ya por entonces anciano y enfermo.

Palabras clave: Goya. Sifilis. Vejiga neurógena. Saturnismo. Historia de la Urología.

Summary.- The famous painter Francisco de Goya y Lucientes (1746-1828) suffered during his life one or several diseases, the nature of which has not been determined with certainty. The partially documented morbid episodes that happened during the years 1792-1793 in Seville and Cadiz, 1819 in Madrid, and 1825 in Bordeaux could be related. In the latter one, the urological signs and symptoms the distinguished patient presented have been demonstrated.

The objective of this paper is to propose the hypothesis of neurosyphilis' dorsal tabes responsible for the voiding disorders he presented in Bordeaux in the spring of 1825, having as a resource Goya's "diplomatario", with the letters and documents that have been collected and made known to date, with the purpose of using an inductive-deductive method for their study and interpre- 
tation, setting an interrelation between these valuable sources with both the medical knowledge of the period and the current, particularly in urological features, and reviewing the available bibliography on that topic, with the natural reserve about giving a retrospective diagnosis which cannot be completely true due to its inherent characteristics.

In the same way, and as a complement, we include a brief review of some circumstances and characters that surrounded the artist in France to help to incardinate and better understand the personality of Goya, already old and sick at that time.

Keywords: Goya. Syphilis. Neurogenic bladder. Saturnism. History of Urology.

\section{INTRODUCCIÓN}

El dos de mayo de 1824, don Francisco de Goya (Fuendetodos, 1746 - Burdeos, 1828) elevó al rey don Fernando VII, por conducto reglamentario, solicitud de licencia para ausentarse de España justificándola en la conveniencia de someterse a tratamiento hidroterapéutico en Francia, concretamente en el balneario de Plombières, cuyas aguas salutíferas le habían sido, supuestamente, pues no consta adjuntara informe clínico ni certificado médico a su instancia, recomendadas por los facultativos que atendían sus dolencias en Madrid. El día anterior, el Rey había concedido y decretado una amplia y generosa amnistía política.

A esta necesidad o conveniencia de índole médica, se han propugnado, entre otros motivos, que Goya hubo de abandonar España por razón de su disconformidad o antagonismo político hacia el absolutismo monárquico fernandino (1), por no suscitar su personal estilo estético ningún interés en el gusto del monarca ni en los de la oligarquía aristocrática, social ni académica de aquellos años, cuya referencia era el excelente pintor neoclasicista don Vicente López Portaña (1772-1850). También, por el acoso sutil del Santo Oficio, tanto por el presupuesto anticlericalismo de Goya como por su adscripción militante a la masonería, incluso por su presunta participación o apoyo al Pronunciamiento (1 de enero de 1820) y al régimen liberal promovido por don Rafael del Riego (1784-1823) como por su inconveniente relación de intimidad con la joven casada doña Leocadia Zorrilla de Weiss (1788-1856), cuya paternidad de dos (Guillermo y Rosario) de los tres hijos nacidos de la joven señora le ha sido atribuida. Los deseos de viajar y visitar Francia; vivir alejado, autoexiliado, de una España que ya ni le atraía ni aclamaba como artista, disfrutar su vejez en la compañía de su pareja y los hijos de ésta sin tener que sufrir los desaires, críticas, el descuido o la desafección de su propio hijo y de su nuera y poder relacionarse y encontrar amparo en uno de los grupos sociales españoles, antiguos "afrancesados", extrañados de la Patria y afincados en la nación vecina, afín a sus convicciones y con quienes, además de lazos ideológicos, pudieran vincularle los de una sincera y cariñosa amistad.

Sea por lo que fuere, Goya salió de Madrid hacia finales del mes de junio de 1824, si solo o acompañado de quien o quienes se desconoce, con la excusa o intención de tomar las aguas del balneario de Plombières, lo cual, bien porque la causa aducida era incierta, porque una mejoría en su salud le animara a posponer el tratamiento prescrito, o por otras indeterminadas circunstancias que lo frustraran, no procedió a concretar y realizar el que era objeto de su viaje (2).

\section{MATERIAL Y MÉTODOS}

Goya redactó un escrito, fechado el 2 de mayo de 1824, que elevó al rey don Fernando VII, siendo tal el único y exclusivo documento en el que el artista acredita y solicita a Su Majestad ausentarse de España, por recomendación médica, por un periodo de tiempo concreto y con intención de someterse a tratamiento $(3,4)$ en Plombières para "mitigar las enfermedades y achaques que lo molestan en su avanzada edad, por recomendación facultativa, por término de seis meses y con abono de sus sueldos por entero". Con gran prontitud, para tratarse la cuestión de un "asunto de Palacio", el 30 de mayo, firmado y fechado en Aranjuez, la mayordomía remitió informe al sumiller de corps notificando el beneplácito y la aprobación del monarca a lo que le solicitaba su pintor para que se le diera traslado al interesado, haciéndose constar reglamentariamente que, para mantener la percepción de sus haberes debía remitir - presentar su apoderado a la Tesorería, mensualmente, la correspondiente "fe de vida" $(5,6)$.

A finales de junio de 1824 Goya partió hacia Francia siguiendo la carretera principal por Burgos, teniéndose constancia de su entrada en territorio galo el 24 de junio por comunicación de la subprefectura de Bayona al ministerio del Interior de Francia, en Paris $(7,8)$, y el 27 del mismo mes por carta del dramaturgo "afrancesado" y exiliado don Leandro Fernández de Moratín (1760-1828) al común amigo de ambos, el clérigo don Juan Antonio 
Melón $(9,10,11)$ : "Llegó en efecto Goya, sordo, viejo, torpe, débil, sin saber una palabra de francés y sin traer un criado (que nadie más que él lo necesita), y tan contento y tan deseoso de ver mundo".

Sin embargo, su destinos no fueron precisamente ni Burdeos ni el balneario de Plombières, pues el 30 de junio, transcurridos unos pocos días de descanso en la capital bordelesa ya se encontraba Goya confortablemente instalado en París, concretamente en el hotel Favart de la rue Marivaux, 5. Y en la capital de Francia permaneció dos meses aproximadamente, pintando, visitando la ciudad y a amigos, conocidos y parientes que allí residían por diferentes circunstancias. La policía francesa vigiló sus pasos, sus contactos y su actividad durante la estancia, en virtud de la condición de alto funcionario que Goya tenía en la Corte de España por ser pintor del Rey y los antecedentes colaboracionistas y anti-fernandinos de muchos de los personajes que se habían refugiado en París. Mas la policía, en sus informes, ni detectó ni reportó ninguna actividad sospechosa o inconveniente de naturaleza social o política en que incurriera el pintor, erró en la verdadera edad del maestro, pues le atribuyó sesenta años en lugar de los setenta y cuatro que contaba, acertadamente les pareció su aspecto muy envejecido, y, salvo su extremada sordera, no refirieron ningún problema de salud ni visita a facultativo alguno (12).

Con seguridad, pues de esta fecha $(28$ de octubre de 1824) es la carta que el pintor envió a su amigo Ferrer en París (13), Goya se encontraba de regreso e instalado en Burdeos, en el número 24 de Cours de Tourny, tal como él mismo acredita en la posdata, acompañado de doña Leocadia Zorrilla y Galarza de Weiss, y dos hijos de esta señora, Guillermo (n.1811) y Rosario (1814-1856), atribuida su paternidad a Goya sin justificación documental alguna desde que el biógrafo bordelés Jules Delpit escribiera "se refugió en Burdeos llevando consigo a la señora Weiss y a la señorita Rosario Weiss que pasaba por ser hija de Goya, lo que su padre legal, se decía, no había querido reconocer", pues, aunque tal no suponga seguridad absoluta, en las partidas de bautismo de la parroquia de San Ginés de Madrid, así como en la de inhumación de don Isidoro constan ambos como hijos legítimos del matrimonio (celebrado en Madrid, el 10 de octubre de 1807) de don Isidoro Weiss(1782-1850) y doña Leocadia Zorrilla $(14,15)$. Goya se integró en la numerosa y bien avenida colonia española en Burdeos, conformada por ex políticos, literatos, dramaturgos, artistas y sus parientes políticos los Goicoechea.

Los meses volaron y su permiso oficial expiraba. En Madrid, Francisco Javier, en nombre de su padre, elevó el 28 de noviembre de 1824 un nuevo escrito a S.M (16), en el que dice Goya que "aunque he hallado algún alivio (en Plombières) me dicen los facultativos de ésta que necesito tomar a principios de primavera las aguas y baños de Bagnères con lo cual puedo esperar el restablecimiento de mi salud".

El pintor, en documento oficial elevado al Rey por delegación, faltaba una vez más a la verdad. En la Corte era perfectamente conocido, por los informes remitidos de la policía, que Goya no había puesto sus pies en el balneario de Plombières, en la comarca de los Vosgos-Lorena, cuyas aguas sulfato-cálcicas, sulfato-sódicas y sulfurosas, como las españolas de los establecimientos termales de Trillo, Ledesma, Sacedón o las Caldas de Cataluña, se empleaban para tratar, entre otros diversos trastornos, el saturnismo, intoxicación bien conocida que con muy alta probabilidad afectó al pintor $(17,18,19)$. Que su estado de salud era satisfactorio o correspondiente a su edad cronológica. Que en París había paseado libremente por lugares públicos, frecuentado a sus amigos, muchos antiguos afrancesados, constitucionalistas y liberales anti-fernandinos, pintado y dibujado, visitado el vanguardista para su época Salón Nacional y admirado en él las pinturas de Ingres, Delacroix, Constable, Bonington, Gérard, Prud'hon y Géricault. Que había regresado a Burdeos sin contratiempo alguno y que residía, si a aquella convivencia quiere atribuirse tal adjetivo, amancebado. En su escrito de solicitud de prórroga por poderes sustituye Plombières por el balneario pirenaico de Bagnères, a donde jamás tampoco acudirá, y no olvida recordar a Su Majestad se le mantenga el sueldo íntegro, el cual percibía en Madrid su habilitado don Gabriel Ramiro a quien había otorgado poder notarial ante el escribano don Francisco Villacampa el 19 de febrero de 1824 (20). Sin embargo, Goya, consciente de haber faltado a la verdad o de no haber cumplido debidamente el alegato en que se fundamentaron su instancia y la real licencia, confiesa por carta a su amiga la duquesa de San Fernando (21), al respecto de la prórroga, su incertidumbre que el Rey se la conceda; e igualmente a su hijo, a quien así se lo manifiesta el 24 de diciembre de 1824 (22): "y también se me ocurre si se me abrá negado la prórroga lque nada se me daría como no me ubieran quitado el sueldo) por que me pondría en camino por mas mal tiempo que hiciese".

No obstante su temor, con fecha 13 de enero de 1825 se le concedió a Goya la prórroga solicitada sin menoscabo de sus haberes, tal como era su deseo (23). No había, pues, según lo visto, marchado Goya a Francia para sanar sus supuestas dolencias, las cuales, de haberlas presentado, igualmente pudo tratarlas sin salir de España. Además, como 
pintor de cámara, tenía derecho a ser atendido por los médicos de la Corte que eran, naturalmente, los más cualificados de la profesión. Tampoco cabe razonablemente considerar que su salida de España obedeciera a razones políticas o que fuera perseguido por motivos ideológicos, pues, de haberlo sido, ni hubiera solicitado licencia ni prórrogas; si lo hubiera hecho, no se le hubieren concedido, ni menos aún mantenido el sueldo. Igualmente, que se autoexiliara como protesta al retorno del absolutismo, la abolición de la Constitución y la ocupación del territorio nacional por el ejército francés en 1823 en virtud de lo acordado y suscrito por los aliados en el artículo $4^{\circ}$ del Congreso de Verona, para "poner fin a la anarquía española". Al contrario, siempre don Fernando VII , a éste respecto, entendió y atendió lo que el anciano y genial pintor elevó a su real y graciosa potestad, condescendiendo con beneplácito. Además, las intenciones de Goya por salir de España, o al menos de Madrid, se documentan de muchos años antes, cuando ya en 1819, con motivo del último encargo de pintura religiosa efectuado por la orden de San José de Calasanz, "La Ultima Comunión de San José de Calasanz" (24-Gudiol nº

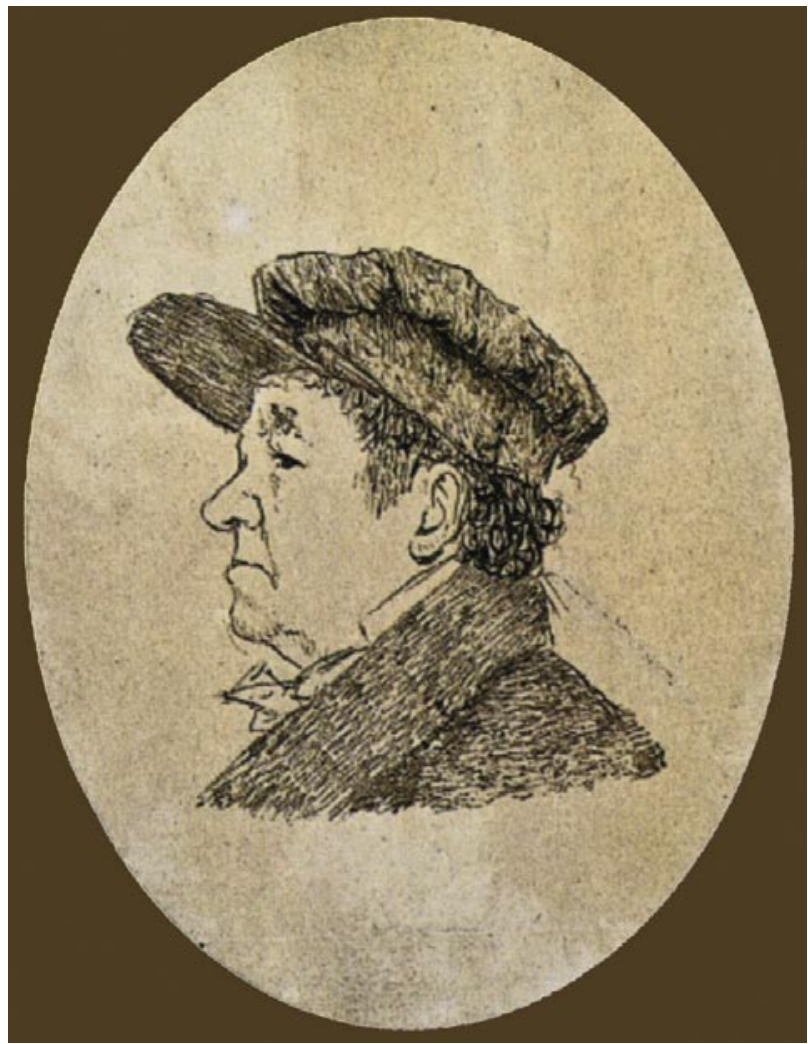

FIGURA 1. Goya, autorretrato a pluma y tinta sepia a la edad de 78 años. 1824
694. $250 \times 180$. Madrid.), se dirigió al padre rector del colegio de San Antón, don Pío Peña, regalándole la pequeña tabla "Cristo en el Monte de los Olivos" (Gudiol no 696. 47x35. Madrid) con la siguiente nota manuscrita fechada en el mes de agosto $(25$, 26): "Aquí le entrego a Ud. este cuadro que dejo para la comunidad y que será lo último que haré yo en Madrid".

Pero lo cierto es que Goya continuó residiendo en Madrid un lustro más sin constar que fuera perseguido ni molestado por "el regreso diabólico de la monarquía absoluta" ni por la "Iglesia codiciosa y amoral" (27), ni tampoco consta que durante el denominado Trienio Liberal (1820-1823) contribuyera el pintor al Pronunciamiento o sublevación de Riego con obra, propaganda o manifestaciones personales pero, siguiendo las tesis que ya clásicamente propusieron los primeros biógrafos extranjeros de Goya $(28,29)$, el anticlericalismo militante, así como la propaganda política liberal y la lectura parcial de las circunstancias de aquellos turbulentos años generalmente se ha ofrecido la salida de Goya de España envuelta en un halo de antagonismo político.

lgualmente, el pintor había residido en Madrid durante la Guerra, viajó a Zaragoza después de su primer Sitio en 1808, y posiblemente también a Piedrahita con motivo de la batalla de los Arapiles (1812); tuvo que "cohabitar" forzosamente con el gobierno del rey José pero superó en los primeros meses de la reinstauración borbónica, quizá no sin dificultades y con influencias benevolentes, los severísimos procesos depurativos tanto políticos como inquisitoriales, a diferencia, por ejemplo, del excelentísimo primer pintor y académico don Mariano Salvador Maella (1739-1819), a quien se le retiraron honores, empleo y sueldo (30). Por todo ello, no es posible concluir en uno o varios motivos fidedignos causales de la salida de Goya de España, debiendo conformarnos con el único que él mismo alegó, no obstante ser muy posiblemente espurio: la enfermedad.

Si inmediatamente antes de abandonar Madrid Goya continuó pintando, en Francia no descansaron sus lápices ni pinceles, prosiguiendo infatigablemente con su producción pictórica y gráfica: retratos, dibujos, miniaturas y litografías. Su aspecto, al llegar a Francia, nos lo ofrece en su pequeño autorretrato (Figura 1) a pluma y tinta sepia $(7 \times 8$. Prado $n^{\circ}$ inv. 483), tocado de gorra de visera, en similar actitud y mismo perfil que el del grabado frontis de "Los Caprichos" (Figura 2), realizado hacia 1799, aproximadamente un cuarto de siglo de diferencia entre ambos. Por carta de Moratín al abate don Juan Antonio Melón, de fecha 14 de abril de 1825 (31) 
sabemos que por aquellos días: "Goya, con sus setenta y nueve pascuas floridas y sus alifafes, ni sabe lo que espera ni lo que quiere: yo le exhorto a que se esté quieto hasta el cumplimiento de su licencia... desde que está aquí no ha tenido ninguno de los males que le incomodaban por allá; $y$, sin embargo, a veces se le pone en la cabeza que en Madrid tiene mucho que hacer, y, si le dejaran, se pondría en camino sobre una mula zaina, con su montera, su capote, sus estribos de nogal, su bota y sus alforjas".

Sin embargo, solamente mes y medio más tarde, sus médicos bordeleses firman el muy interesante certificado que esta vez sí Goya adjuntará en el mes de junio, igualmente representado por su hijo Francisco Javier (32), para solicitar y obtener su tercera prórroga, en ésta ocasión concedida por un año de duración (33). El certificado (34), originalmente redactado en francés y traducido en Madrid antes de ser adjuntado a la pertinente instancia de solicitud, lleva fecha de 29 de mayo de 1825 y se expresa en los siguientes términos:

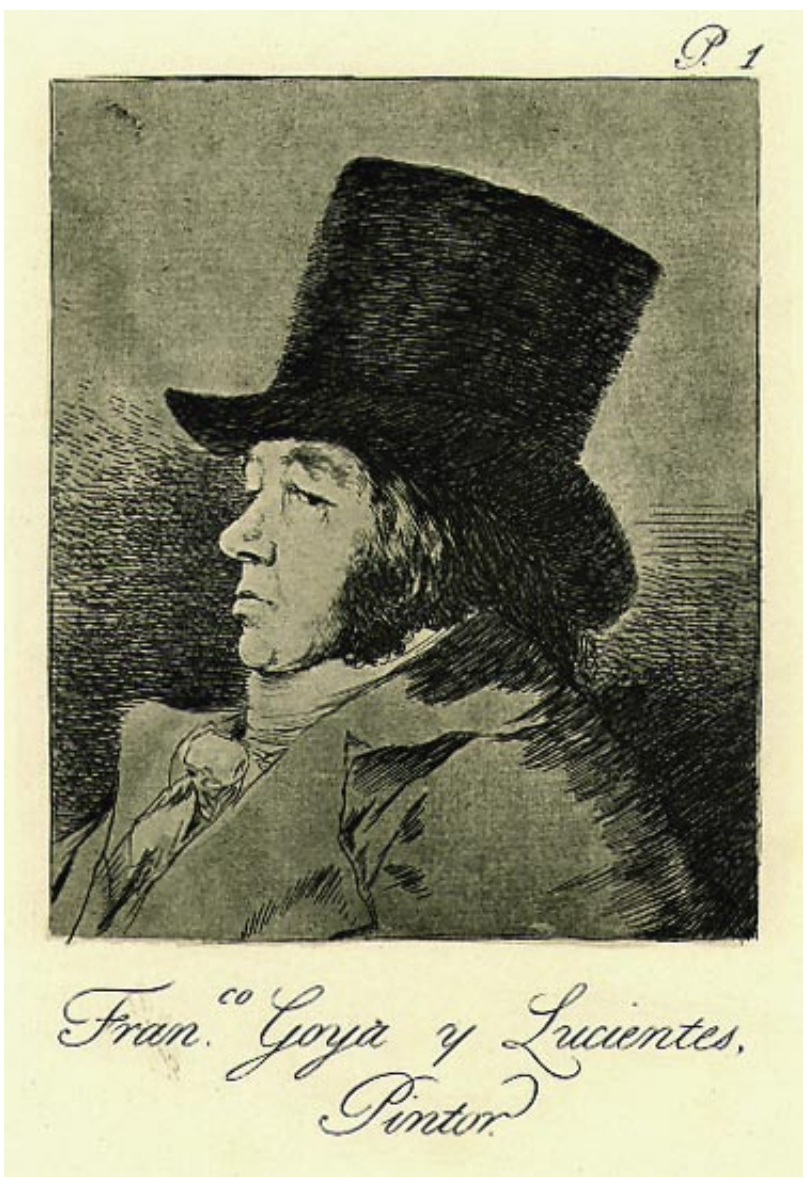

FIGURA 2. Goya, autorretrato, grabado al aguafuerte y aguatinta. 1797.

\section{De Lafarque Dopude y L'Oliveira, médicos.}

Nos los infrascritos Doctores en Medicina; Certificamos que Don Francisco Goya, de edad de ochenta años y Pintor de su Magestad Católica se halla atacado actualmente de Perlesía de la Vejiga de la Yschurie que es la consecuencia de ella; entre las causas que han provocado esta enfermedad tan peligrosa como incómoda es una de ellas bastante principal y visible: que habiendo enseguida atacado a los sentidos del oido y de la vista ha hecho igualmente las fibras de la Vejiga rígidas y por tanto menos susceptibles de ser escitadas por su estimulo natural; esta afección con los progresos lentos y continuos y el aplanamiento de la edad abanzada arrastra consecuencias muy funestas tales como el endurecimiento squirrensa de la vejiga y un tumor voluminoso al Pèrinee lo que anuncia con sentimiento que la Enfermedad es incurable y que el enfermo se halla actualmente en la imposibilidad absoluta de hacer ningun egercicio. En fé de lo cual hemos dado la presente Certificación para que sirva en lo que fuere de derecho.

Burdeos el día veinte y nueve de Mayo de mil ochocientos veinte y cinco.

Lafarque Dopude, Médico. L'Oliveira, Doctor en Medicina.

Don José Paspati Bracho Oficial mayor, habilitado por Su Magestad interinamente para el despacho de la Secretaría de la Interpretación de Lenguas; certifico que la antecedente traducción está bien y fielmente hecha en castellano del egemplar francés que me fué exhibido para este efecto. Madrid veinte de Junio de mil ochocientos veinte y cinco. José Paspati Bracho.

\section{DISCUSIÓN}

Se entiende por Certificación el documento en el que se afirma o asegura la verdad de uno o más hechos. No es la Certificación una Declaración, esto es, la manifestación que bajo juramento presta el médico al juez, en calidad de perito, por causa criminal, civil, o las demás que estén prevenidas por leyes y reglamentos.

Por tanto la certificación es un documento extra-oficial, concretamente ésta que nos ocupa, de carácter enunciativo, que muy posiblemente fue redactada y librada, aunque tal no consta, a instancia del propio interesado, y con un fin u objeto, que debería haber sido simplemente presentarla donde conviniere para, en su caso, y como efectivamente se indica con 
indebida anticipación clínica, surtir los pertinentes efectos. En puridad, sobran en el certificado reflexiones pronósticas o conclusiones de carácter deductivo pues debe restringirse, con estilo lacónico, claro y sintético, a lo puramente descriptivo y esencial de lo que se reconoce en el momento que se redacta y firma.

Estas consideraciones conceptuales resultan importantes para analizar el texto, pues, sin pretender restarle veracidad, debe tenerse presente lo que un autor relevante dejó reseñado a éste respecto: " $E s$ tanto lo que abunda ese documento; es tal el abuso que se hace de él; son tantos los que apelan a éste recurso para eximirse de ciertos cargos, obtener licencias, lograr dietas, etc, que casi no hay español que no sepa cómo y cuándo se dan certificaciones por facultativos. Las gentes creen que los facultativos pueden certificarlo todo, hasta lo que no existe, sin ningún inconveniente; y aquí se prevalen de la amistad, alli de la clientela, de la coacción moral, de las relaciones, de los favores que algunos médicos deben a sus clientes o de su posición particular" (35).

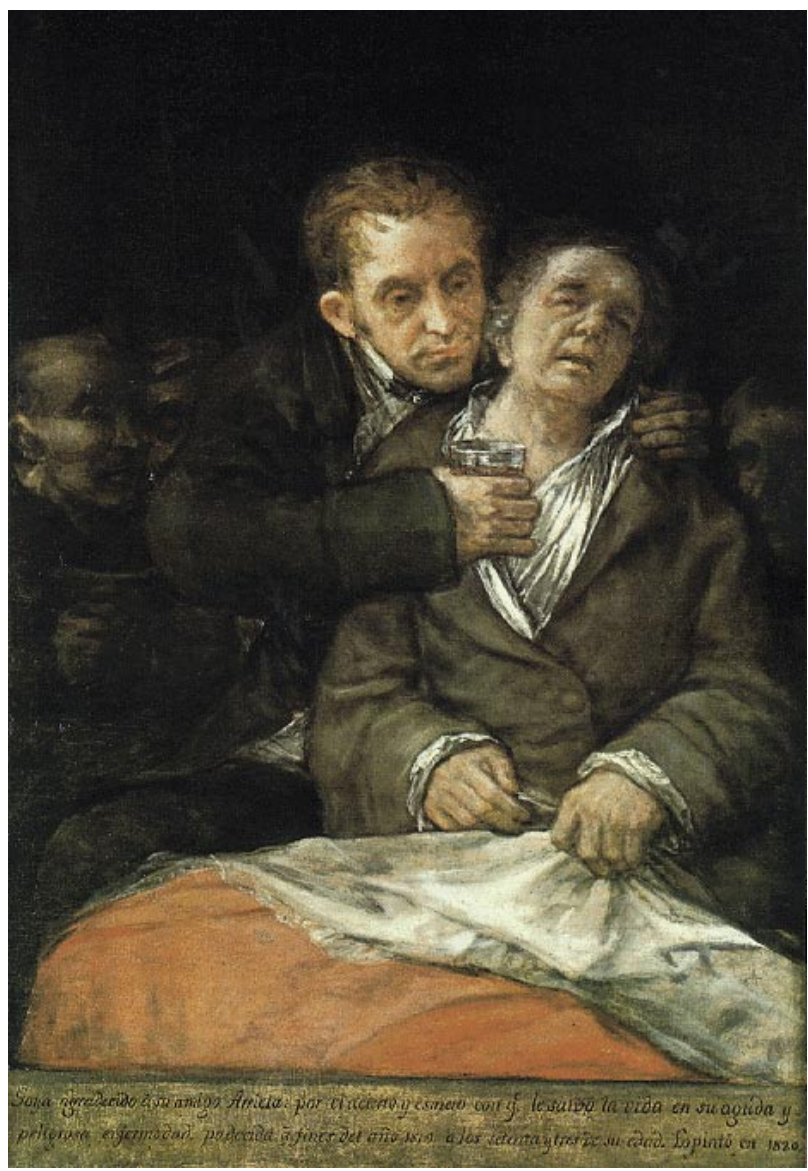

FIGURA 3. Goya, enfermo; autorretrato, atendido por el doctor Arrieta. 1820.
Que Goya enfermó, y de gravedad, lo atestigua Moratín en sus cartas: "Goya ha estado a punto de morir", "Goya escapó por esta vez del Aqueronte avaro". Que la enfermedad duró pocas semanas, las fechas de éstas misivas, de diez y seis y veintiocho de junio de 1825, así como que el pintor se recuperó y volvió al trabajo: "está muy arrogantillo y pinta que se las pela, sin querer corregir jamás nada de lo que pinta" (36). En efecto, Goya sobrevivió a esta crisis tres años, regresó incluso a Madrid una breve temporada en el verano de 1827 y tuvo tiempo y disposición para dibujar, retratar al óleo y dedicarse a las litografías de "Los Toros de Burdeos" ¿ Cuál pudo ser entonces la naturaleza del episodio mórbido sufrido en 1825, documentado por sus médicos? De la certificación de los galenos franceses, con las debidas reservas, pueden extraerse las siguientes conclusiones:

1․- Que padecía "Perlesía" (parálisis) de la vejiga, de carácter arrefléxico-aferente (sensitivo).

2. ${ }^{\text {.- }}$ Que la retención de orina (Ysquiuria) era consecuencia de la Perlesía.

3.- Que la Perlesía estaba relacionada con la misma enfermedad de base que había afectado a los sentidos de la vista y del oído con anterioridad.

4⿳. - Que esta enfermedad es crónica (progresión lenta y continua), peligrosa, incómoda, visible (evidente) e incurable, y sus consecuencias (pronóstico) funestas.

5․- Que le impide absolutamente hacer ejercicio (postrado, incapaz de incorporarse por sí mismo o caminar).

6".- Que se asocia igualmente a "un tumor voluminoso" en el perineo, $y$ :

7‥- Y que, no obstante describir signos y síntomas, y vincularlos, se omite, o intencionadamente se oculta, el diagnóstico de la enfermedad.

Necesariamente, antes de proseguir, deben ser brevemente repasados los antecedentes clínicos más significativos y documentados en la biografía del pintor. La enfermedad inmediata anterior a ésta de Burdeos que encontramos es la padecida en Madrid a finales de 1819, que fue atendida por el doctor don Eugenio García Arrieta. Una vez restablecido, Goya, recordándose enfermo, se autorretrató junto a su médico el doctor Arrieta (Gudiol 697. 117x79. Minneapolis), que le abraza sosteniéndole la cabeza a la vez que le ofrece un vaso cuyo contenido parece rechazar el pintor, inscribiendo la siguiente leyenda manuscrita: "Goya agradecido a su amigo Arrieta 
por el acierto y esmero con qe le salvó la vida en su aguda y peligrosa enfermedad padecida a fines del año 1819 a los setenta y tres años de su edad. Lo pintó en 1820" (Figura 3), pudiendo advertirse en el autorretrato de Goya ciertas similitudes con el que se realizó sobre tabla (Figura 4) en 1815 (Gudiol 637. 51x46. Real Academia de Bellas Artes de San Fernando. Madrid. no inv 669), que posiblemente tomó como modelo. De Arrieta se conoce que era natural de Cuellar (Segovia), que ejerció la medicina en Madrid adquiriendo fama y una selecta clientela aristocrática y que en 1820 fue comisionado por el gobierno para estudiar "la peste de Levante" en las costas de África. Según documentos que permanecieron en poder de los descendientes de Arrieta, se habla en ellos de fiebres tifoideas (tubardillo), y que Goya presentó cefalea, fiebre alta, delirios y parálisis parcial (37).

Hay que remontarse a finales de 1792 y principios de 1793 para encontrar el episodio mórbido, casi mortal, que cambió radicalmente la vida de Goya y le dejó como terrible secuela la sordera absoluta acompañada de acúfenos intermitentes. Esta enfermedad se declaró en Sevilla, y las circunstancias del viaje emprendido por Goya hacia Andalucía, sus motivos y la fecha en que lo emprendió no están aún completamente dilucidadas. La primera noticia al respecto se tiene por la carta de contestación remitida

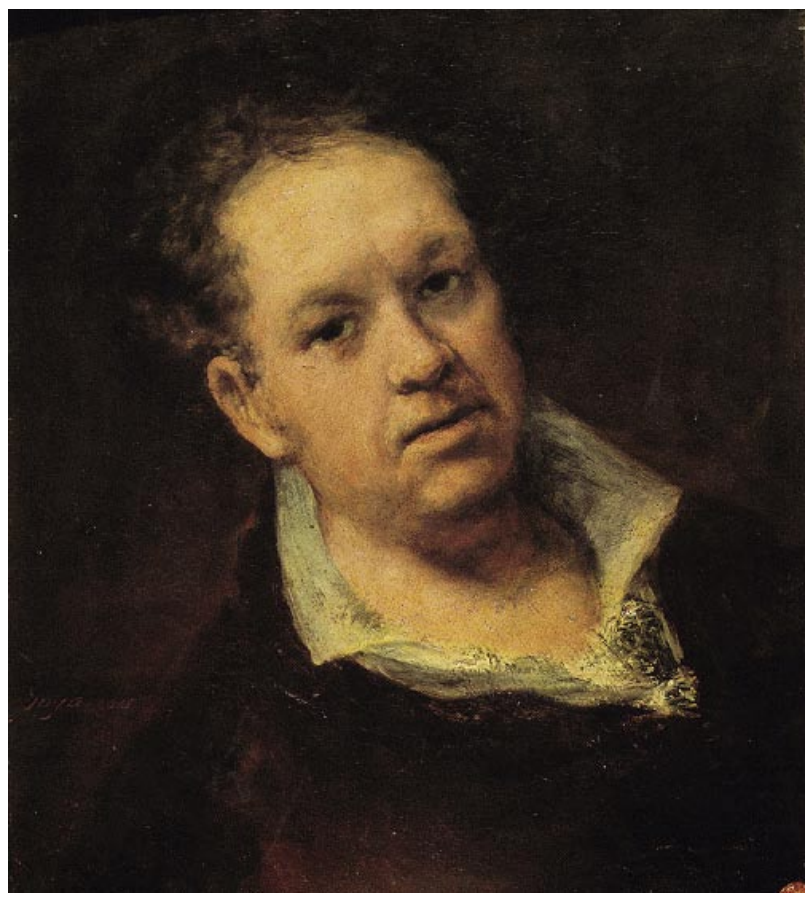

FIGURA 4. Goya, autorretrato. 1815 desde Zaragoza por el fraternal amigo de Goya, don Martín Zapater y Clavería (1747-1803), al común amigo don Sebastián Martínez y Pérez (1747-1800), que recibió al pintor en su residencia de Cádiz, de fecha 19 de enero de 1793 (38): "Amigo y dueño: La estimada de Vuestra Merced de 5 del corriente me ha vuelto a dejar en el mismo cuidado de nuestro amado Goya, que la primera que recibí, y como la naturaleza del mal es de las más temibles, me hace pensar con melancolía sobre su restablecimiento". Desafortunadamente, la carta que signó y fechó don Sebastián el 5 de enero no consta.

La siguiente es la carta que don Sebastián Martínez dirige desde Cádiz a don Pedro Arascot y Sánchez (1741-1806), secretario del sumiller de corps, en Madrid, de fecha 19 de marzo de 1793 (39): "Muy Señor mio y mi Dueño: Mi amigo don Francisco de Goya salió de esa corte como a Vuestra Merced consta, con ánimo de ver esta ciudad y las del tránsito, gastando en esto los dos meses que traía de licencia; pero la suerte quiso que cayera malo en Sevilla, y creyendo que aquí tendría más auxilios se resolvió a venirse con un amigo que lo acompañó, y se me entró por las puertas en malísimo estado, en el que subsiste sin haver podido salir de casa...me temo que sea asumpto largo, en cuio caso me tomo la livertad de molestar a V.m., suplicándole tenga la bondad de dezirme si combendrá que Goya imbie certificazión de los facultatibos para hacer ver su estado, y que pueda obtener prórroga...Post Data. Acaban de salir de casa el Protomédico don Josef Larbarera y el cirujano don Francisco Canibel quienes hubieran puesto la Certificación, pero les he dicho lo suspendan hasta que Vuestra Merced tenga la bondad de responder".

La tercera es la carta de respuesta de don Sebastián Martínez a la que recibió de don Martín Zapater lésta de fecha 19 de marzo, perdida o en paradero desconocido) el 29 de marzo (40): "Amigo y Dueño:... nuestro Goya sigue con lentitud aun que algo mejorando. Tengo confianza en la estación y que los baños de Trillo que tomará a su tiempo lo restablezcan. El ruido en la cabeza y la sordera nada han cedido, pero está mucho mejor de la vista y no tiene la turbación que tenía, que le hacía perder el equilibrio. Ya sube y baja las escaleras mui vien y por fin hace cosas que no podia".

Y la cuarta y última es la carta de don Martín Zapater, desde Zaragoza, al cuñado de Goya, don Francisco Bayeu, en Madrid, de fecha 30 de marzo de 1793 ( 41 ): "Mi querido Paco:... A Goya, como te dije, le ha precipitado su poca reflexión, pero ya es preciso mirarlo con la compasión que exige su desgracia y como a un hombre enfermo, a quien es 
menester procurar todos los alivios, como tú lo has hecho, consiguiéndole la licencia para procurar el recobro de su salud, y nada menos debía esperar de tu buen corazón y cristiandad".

Firmada por Goya, y fechada curiosamente en Madrid, el 17 de enero de 1793, existe una carta que el pintor dirige a uno de los administradores de los señores duques de Osuna (42): "Muy estimado señor don Manuel de Cubas: Le he de merecer a Vuestra Merced el fabor de acer presente a su Excelencia que he estado dos meses en cama de dolores cólicos, y que paso a Sevilla y a Cádiz con licencia, y que suplico a su Excelencia si quiere dignarse que por su recomendación o su apoderado, pueda yo tomar algún dinero en Sevilla".

Pero la única licencia de la que hay constancia es la notificación que por este asunto dirige, en enero de 1793, en Palacio, sin consignar día, el señor duque de Frías a don Francisco Antonio Montes, cuando el pintor ya se encontraba en Cádiz (43): "El Rey se ha dignado conceder á Don Francisco de Goya dos meses de licencia para que pueda pasar á Andalucía a recobrar su salud".

Solamente se ha conservado en el "Diplomatario" de don Martín Zapater una carta de don Sebastián Martínez; y, si Goya escribió alguna o la dictó y dirigió a su querido amigo, ninguna. El heredero de los bienes y archivo de Zapater, su sobrino don Francisco Zapater y Gómez (1820-1897), reivindicó la vida y obra de Goya frente a los biógrafos extranjeros, a los cuales estimó acertadamente como parciales cuando no denigratorios, inveraces y propaladores de leyendas sin fundamento, que aun persisten, como muy posiblemente expurgó del "Diplomatario" de su tío cartas o documentos inconvenientes o comprometedores, silencia (44) el período de tiempo entre febrero de 1790 y abril de 1794, pero no obstante no olvida afirmar que posee diversas cartas en su colección (de una serie de 132) que corresponden a la que él mismo clasifica como "tercera época" (desde 1789 a 1801), concluyendo: "He formado estos apuntes o noticias biográficas con el solo objeto de vindicar a Goya, despojando su apellido de ese falso renombre que mancha su gloria, y no cabe calificar a tan elevado genio como un escapado del siglo XVI en cuanto a los vicios".

Goya se recuperó de esta terrible enfermedad, regresó a Madrid hacia abril o mayo de 1793 y su primer autorretrato, hasta 1982 propiedad de los señores condes de Villagonzalo quizá sea aquel en el que se representa de cuerpo entero (Figura 5), pintando en su estudio, de pie y a contraluz (Gudiol 96. 40x27.Real Academia de Bellas Artes. Madrid. $n^{\circ}$ inv 1166), y, con seguridad, el ya mencionado del frontis de los grabados de Los Caprichos. Nada sabemos de los tratamientos que al enfermo se le recomendaron; de los síntomas y la evolución seguida, solamente lo reseñado en las cartas de aquel tiempo cuyas dataciones, por no ser correlativas o subsecuentes, se ha propuesto para ajustarlas a un orden cronológico que las fechas están confundidas o son erróneas (45). Acertó Goya en dirigirse, o quienes decidieron trasladarle, a Cádiz en demanda de asistencia médica de calidad, pues en la ciudad atlántica, por razón del Comercio y de la Armada, prestaban sus servicios profesionales afamados especialistas miembros de relevantes y pioneras corporaciones científicas. De don Francisco Canivell (1721-1796) se conoce nació en Barcelona, estudió Medicina en Cervera y ejerció la Cirugía en Sevilla y Cádiz, llegando a ser Cirujano de Cámara del Rey y Cirujano Mayor de la Armada, alcanzando fama como experto urólogo-litotomista, autor de un método personal diagnóstico de la litiasis vesical $(46,47)$.

Una vez de regreso en la Villa y Corte, es razonable presuponer que Goya continuaría siendo atendido y tratado con objeto de recuperar la audición. Y que, muy posiblemente, uno de los galenos

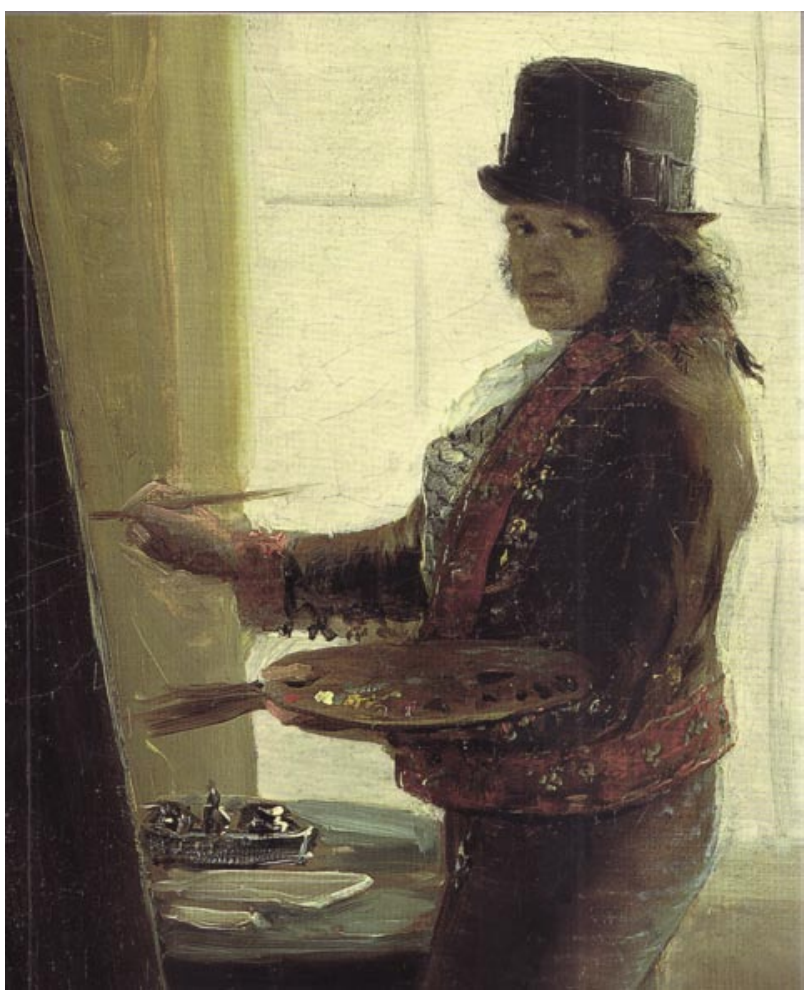

FIGURA 5. Goya, autorretrato en su estudio. h. 1793 (datación imprecisa). 
que le prestaría asistencia fuese, pues el pintor, por ser empleado de la Casa Real (Pintor de Cámara) tenía "derecho a médico", don Juan Naval, médico de familia de S.M.C., de cuya biografía es muy poco lo que se conoce y sus datos o actividad profesional permanecen inéditos, si es que se conservan, en el Archivo del Palacio Real de Madrid. Médico "de familia" en el sentido de familia que en el Antiguo Régimen se daba a tal denominación, "in extenso", incluyéndose en la "familia" del Rey no solamente familiares y parientes, sino desde los múltiples y diversos maestros, oficiales y empleados de la Corte hasta los criados, sus viudas y huérfanos. Don Juan Naval, médico de la llustración, es autor del "Tratado Médico-Quirúrgico de las Enfermedades de la Vejiga" (Imprenta Real. Madrid. 1799) en cuyo tomo II, parte IV, sección XV toca las "parálisis de la Vejiga"; en la sección XXI, "la retención de orina en la vejiga"; en la sección XXIII habla "del cateterismo", y en la sección VII de la parte V, "de los tumores urinarios que se forman en el perineo" (48). Pero los padecimientos que estudia y publica Juan Naval no los presentará Goya hasta muchos años después. Sí, la sordera, a la que Juan $\mathrm{Naval}$, como espléndidamente ha revisado el doctor Vallés Varela (49), igualmente dedicó atención y estudio, así como a las enfermedades de los ojos, pues suyos son igualmente el "Tratado Físico-Médico Quirúrgico de las Enfermedades de los Oidos" (Imprenta Real. Madrid. 1797) y el "Tratado de la Ophtalmía y sus especies" (Imprenta Real. Madrid. 1796). Naval distingue en su texto otológico la "disecoia" (hipoacusia de trasmisión), las distintas "paracusis" (reclutamiento, hiperacusia, diploacusia y la paracusia de Willis) y la "cofosis" (anacusia o sordera) por afectación intrínseca del nervio auditivo, cuyas causas atribuye a un origen tóxico (en concreto, el mercurial), el venéreo (específicamente el "gálico" o sifilítico) y el "pletórico" (vascular o isquémico). Los ruidos o acúfenos, graves o agudos, los identifica igualmente secundarios a la afectación del nervio auditivo por las mismas etiologías, y el vértigo a un origen central, cerebral, desvinculado del laberinto. Pero añade que la asociación de la cofosis (sordera) a los ruidos y al vértigo "dan mucha luz para descubrir la causa de la enfermedad".

Y esta célebre "enfermedad de Goya" ha sido relacionada con un largo repertorio de posibles diagnósticos, entre los que dos son preeminentes: El saturnismo, intoxicación por el plomo o "cólica de los pintores", y el mal gálico, lúes o sífilis.

Resulta verosímil el saturnismo en su calidad de enfermedad profesional, conocida de antiguo (50), perfectamente caracterizada y descrita $(51,52)$. El albayalde (hidroxicarbonato de plomo), el litargirio (monóxido de plomo) y el minio (tetraóxido de plomo) eran productos imprescindibles para moler, mezclar y obtener colores, en combinación con el carmín, ocres, tierra roja, aceite de linaza y de nueces. Goya adquiría el albayalde por arrobas, en sacos, a su droguero madrileño don Manuel Ezquerra y Trápaga, y Goya, él mismo y con su ayudante moledor, Perico Gómez, a quien abonaba un jornal de seis reales de vellón, preparaban las pinturas en el taller, cortaban los lienzos y claveteaban éstos en los bastidores, fabricaban pinceles, brochas, espátulas, espatulinas y todo lo necesario, artesanalmente, para el ejercicio de su arte.

Tanto por vía respiratoria como digestiva y transcutánea, siendo diferentes las tóxico-cinéticas de cada una de éstas vías de impregnación, el plomo penetra en el organismo y se acumula hasta alcanzar plumbemias elevadas, tóxicas, que provocan un abigarrado cuadro clínico-sintomático desde manifestaciones muy leves e inespecíficas hasta, en el otro extremo, hipertensión intracraneal, convulsiones, insuficiencia hepato-renal, coma metabólico y la muerte: sin embargo, son los derivados orgánicos del plomo, el tetraetilo y el naftenato de plomo, absorbidos por vía cutánea con la dermatitis irritativa consecuente, los que muestran una afinidad prioritaria por el sistema nervioso central siendo, además, relativamente muy bajos los niveles o concentraciones de plomo tanto en sangre como en orina, versus los compuestos inorgánicos, como son el litargirio, el minio, el carbonato, la cerusa y el mismo plomo metálico, distinción toxicológica imprescindible para entender los diferentes cuadros clínicos que provo-

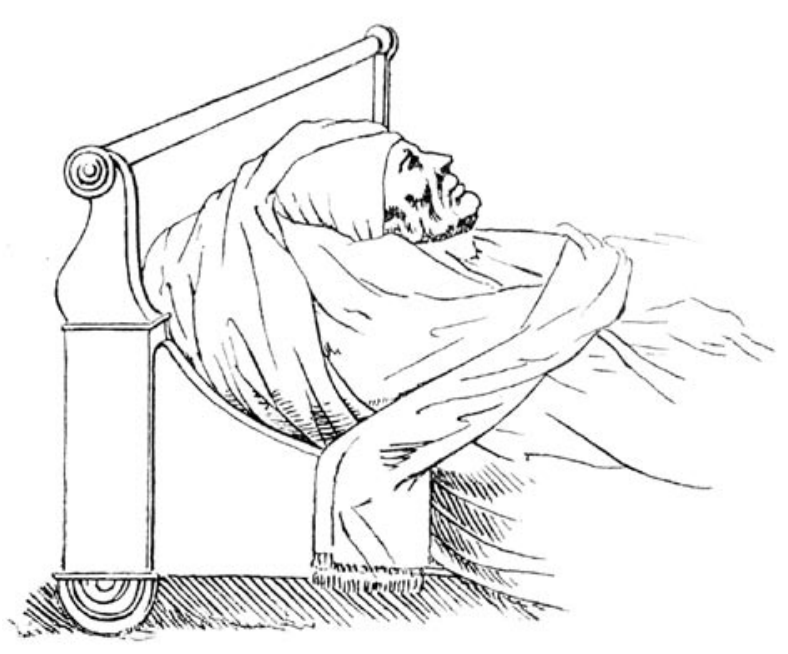

FIGURA 6. Goya en el lecho de muerte, por De la Torre / Botey. 1828. 
can unos y otros, generalmente confundidos por su solapamiento: no obstante estas consideraciones de índole médica, una magnífica revisión del saturnismo como hipótesis mórbida de Goya, excelente y profusamente documentada, se debe a una distinguida erudita española, farmacéutica e historiadora del Arte, cuyo magnífico ensayo (19), aun con alguna que otra inexactitud clínico-patológica, es de obligada referencia en la bibliografía goyesca.

Sin embargo, por ser bien conocida esta enfermedad y sus causas, y en consecuencia previsible y prevenible, resulta dudoso atribuir al plomo todas y cada una de las enfermedades que padeció el pintor a lo largo de su dilatada vida, es decir, que no padeció otras más que el saturnismo, al que incluso se hace responsable del cuadro sincopal mortal que le llevó al sepulcro en 1828.

Sin pretender refutar esta hipótesis, sí resulta muy probable que determinados síntomas y signos que presentó Goya pueden ser vinculados a la intoxicación plúmbica que muy posiblemente padeció crónicamente, pero la enfermedad sobrevenida en Sevilla parece ser que se presentó agudamente, inesperadamente, y que Goya se puso en viaje, por razones indeterminadas, disfrutando una salud aceptable; la carta que firma Goya y en la que dice que ha padecido dolores cólicos en Madrid para cuya recuperación, con licencia, pasa a Andalucía, se contradice con la que don Sebastián Martínez dirigió al cortesano y secretario don Pedro Arascot en la que manifiesta que el motivo del viaje no fue otro que conocer tanto las ciudades andaluzas como las del tránsito (por ejemplo, Córdoba), que enfermó súbitamente en Sevilla y que "un amigo", cuyo nombre omite, pero que bien pudiera ser don Juan Agustín Ceán Bermúdez (1749-1829), extrañado por entonces de la Corte en Sevilla con destino en el Archivo de Indias, le llevó a su casa en malísimo estado (53). Y cautamente, en la misma misiva, don Sebastián Martínez aguarda a recibir instrucciones superiores por si fuera conveniente que los médicos que atendían al pintor redactaran una certificación del estado clínico de Goya, como si temiera que, de no ser imprescindible el certificado, su redacción fuera inconveniente, dando a entender a Arascot que los facultativos lo hubieran hecho siempre y cuando la certificación les fuera exigida con carácter oficial, y no meramente a instancia del interesado.

Por tanto, a la supuesta y no acreditada confusión de fechas de las cartas se añaden razones controvertidas en unas y otras que complican su dilucidación. Téngase en cuenta que Canivell era un médico renombrado y Cirujano de la Armada, que dudosamente se avendría a certificar prevaricando o modificando la realidad que pudo constatar, inmoralidad en la que, caso de incurrir y según fuera el curso que los acontecimientos tomaran en un futuro, pudiera acarrearle severas consecuencias, incluso de carácter penal. Tantas reservas y contradicciones que se traslucen entre líneas no dejan de llamar la atención y promover la incertidumbre que, además del saturnismo, caso que tal fuera la causa, y que si en efecto lo hubiera sido no habría existido inconveniente alguno en acreditarlo, hubiere además otra u otras.

Naval, en su tratado "De las Enfermedades de los Oídos", no considera al plomo, sí al mercurio, como causa de sordera central irreversible y absoluta. Luzuriaga (18), en su "Disertación sobre el Cólico de Madrid" (1796), dice que el plomo puede provocar "ceguera, o la sordera por cierto tiempo". Y los galenos franceses, sin aparente género de duda, relacionaron la sordera y los trastornos visuales 10 hallazgos exploratorios de los reflejos pupilares) con la "perlesía" (parálisis sensitiva) de la vejiga, la "Ysquiuria" o retención urinaria, la imposibilidad de hacer ejercicio y el tumor voluminoso del periné, obviando o evitando, igualmente que Martínez, Larbarera y Canivell en Cádiz, dar un nombre concreto a la enfermedad que parece consideran "evidente". Si Goya padeció saturnismo, enfermedad profesional y en absoluto vergonzante, no existe un sólo documento oficial que lo acredite.

Como tampoco, menos aún, que la enfermedad en cuestión se tratara, si lo fue, del mal gálico, lúes o sífilis, a la cual Naval sí hace responsable de la sordera cuando dice "el gálico inveterado que ataca al oído", enfermedad prevalente, conocida de antiguo (54) y tenida bien presente por la medicina legal y sus peritos (55-59). Los sifilógrafos de aquel tiempo conocían en profundidad las variadas manifestaciones de la sífilis, su prolongada, intermitente, solapada e indeterminada evolución, la sífilis hereditaria, la parasífilis o metasífilis, hoy afortunadamente excepcionalísimas y anecdóticas. Una enfermedad compleja con interrogantes aun no del todo resueltos, lacra de los tiempos anteriores a la penicilina: lesiones indoloras que curaban completamente en apariencia, erupciones dérmicas confundidas con "viruelas"; accidentes cerebro-vasculares propios de la sífilis meningo-vascular que provocaban una mortalidad precoz len torno a la quinta década de la vida) o secuelas sensitivo-motoras $y$, caso de la mujer enferma, infertilidad, abortos, partos prematuros, nacidos muertos a término o sifilis neonatal o infantil, responsable de malformaciones e igualmente asociada a una alta mortalidad pediátrica. Doña Josefa Bayeu y Subías (1747-1812), la mujer de Goya, trajo al mundo y fueron bautizados, al menos los que se conocen, ocho hijos, uno sietemesino (n. 1778) naci- 
do muerto, todos los demás fallecidos tempranamente excepto el último, Francisco Javier (1784-1854), aunque debieron ser muchas más las gestaciones malogradas (60). La medicación hidragírica o mercurial era entonces suficientemente conocida, así como su toxicidad, recurriéndose al mercurio metálico, al bicloruro de mercurio, al protoyoduro de mercurio, al biyoduro, a las fricciones con ungüento mercurial doble o "ungüento napolitano" (manteca de cerdo y mercurio), los emplastos, los baños templados de sublimado, las fumigaciones (vapores calomelanos) y un extenso vademécum terapéutico, al que se añaden las terapias basadas en el iodo, el arsénico y el clorhidrato de quinina. Las aguas sulfurosas sódicas, como las de los balnearios franceses de Luchon, Cauterets, Bagnères y Plombières les Bains, así como las sulfurosas cloruradas sódicas como las de Uriage y Challes, han sido las más renombradas por su carácter adyuvante a la terapia mercurial, así que en estos balnearios, como en los de Trillo o Ledesma en España, coincidían enfermos con muy diferentes patologías.

De las costumbres más o menos libertinas del Antiguo Régimen, y sus enfermedades relacionadas, existen numerosas fuentes literarias entre las que merecen destacarse las de Torres Villarroel (1694-1770), Rousseau (1712-1778), Moratín hijo o su progenitor, don Nicolás (1737-1780), autor de la obrita titulada "Arte de las Putas"(61-65), prohibida por edicto de la Inquisición de Corte fechado el 20 de junio de 1777, con carácter "universal, aun para los que tengan licencia de leer libros prohibidos, por estar lleno de proposiciones falsas, escandalosas, provocativas a cosas torpes, injuriosas a todos los estados del Cristianísimo, blasfemas, heréticas y con sabor de Ateismo y Politeismo" (66), que posiblemente compuso hacia 1770, igualmente autor de la "Carta Histórica sobre el origen y progreso de las fiestas de toros en España" (Pantaleón Aznar Imp. Madrid. 1777). Como la obrita manuscrita e inédita entonces de don Nicolás, prohibidos también por el Santo Oficio estaban los clásicos "Ars Amandi" y los "Remedios de Amor" de Ovidio; textos relacionados con la prostitución, como el italiano "Il putanismo moderno con il novisimo parlatorio" (67) e incluso tratados de medicina, como el de Gigùn titulado "Traite des maladies vénériennes" (68). Moratín padre, don Nicolás, y Moratín hijo, don Leandro, fueron ambos buenos amigos de Goya; del primero se inspiró, muy posiblemente, para componer la serie de grabados de "La Tauromaquia"; con el concurso literario del segundo, "Los Caprichos". Goya muy posiblemente conoció el manuscrito original, o una copia, del "Arte de las Putas", en alguno de cuyos versos (Canto II) se describe el sentir popular al respecto del mal gálico, su vía de contagio, profilaxis y tratamiento.
La hipótesis de la enfermedad luética (69) ha sido enérgica, apasionadamente refutada principalmente en base a consideraciones de carácter moral, religioso y social. Sus detractores consideran la sífilis absolutamente imposible de haber afectado a Goya, contraponiéndola al más socialmente aceptable saturnismo. Pero resulta muy dudoso poder relacionar un brote de saturnismo, tan agudo, con el padecido tardíamente en 1825, y no parece deducirse esto de la certificación médica en lo que afecta a la "perlesía e ysquiuria" las cuales, con las oportunas reservas, pudieran relacionarse con la desmielinización de las fibras de los cordones nerviosos y raíces posteriores de la médula espinal de la tabes dorsal, una vejiga neurógena fláccida por desaferentación, con pérdida de la percepción de llenado y del subsiguiente deseo miccional, coexistiendo durante la "crisis tabética" dolor somático agudo en las extremidades inferiores, incapacidad para caminar en la oscuridad, disociación de las sensaciones (dolor/temperatura), hipo o analgesia segmentaria alternando con hiperalgesia, perdida de la kinestesia y dolores "profundos" (tendón de Aquiles, dedo gordo del pie; testículos). En la tabes, los reflejos profundos de las extremidades inferiores están abolidos o disminuidos y las pupilas se ofrecen a la inspección arreactivas a la luz, pero no a la convergencia (70).

Las sensaciones viscerales del tracto urinario inferior (propioceptivas: distensión, contracción y volumen, y exteroceptivas: dolor, temperatura, tacto) son transmitidas por las fibras axonales aferentes de los nervios pélvicos, hipogástricos y pudendos hacia los centros medulares correspondientes lumbo-sacros y tóraco-lumbares del asta posterior e intermedia o lateral de la médula. Estas aferencias axonales, particularmente las que trasmiten información de volúmen/distensión de la musculatura lisa vesical son mielinizadas tipo "A-delta", y con carácter adyuvante las no-mielinizadas "tipo C" procedentes del urotelio (71), siendo la velocidad de conducción del pulso eléctrico diferente unas de otras (entre 1,3 y 2 metros por segundo). Mientras que las aferencias exteroceptivas ascienden hacia el tálamo, decusándose, siguiendo los haces espinotalámicos contralaterales, las propioceptivas no se decusan, se integran en los cordones posteriores de Goll y Burdach, establecen sinápsis en el área pontino-mesencefálica y de allí siguen al tálamo (72). Este es, resumidamente, el sustrato anatomo-fisiológico afectado por la desmielinización neurosifilítica. Igualmente, debe anotarse que el término "isquiuria" o "iscuria" hacía referencia tanto a la retención urinaria (anuria obstructiva infravesical o supravesical), como a la anuria secretora, estando ya descrita desde principios del XVII por Nicolás Tulp, inmortalizado por Rembrandt (16061669), incluso el de la "iscuria paradójica" (de Tul- 
pius), acompañada de dolor abdominal, precedente de la actual hidronefrosis y anuria o retención urinaria intermitente del riñón único obstruido (73).

Hay que remontarse, afortunadamente, muy atrás en el tiempo para encontrar referencias bibliográficas al respecto de la sintomatología miccional propia de la metasífilis. La vejiga de la tabes, o vejiga sifilíti$\mathrm{ca}$, ofrece en el estudio urodinámico una característica arreflexia del detrusor, una capacidad incrementada y ausencia de deseo miccional, aunque también se han reportado, en casos de afectación suprasacral, una reducción de la "compliance", detrusor hiperefléxico y disinergia detruso-esfinteriana, así como hipocontractibilidad del detrusor y residuo postmiccional elevado (74).

En la serie publicada por Garber y cols. (75) se presentan tres casos de afectación miccional secundarios a neurosífilis, dos varones, de 48 y 71 años, éste con historia de neurosífilis de 35 años de antigüedad, y una mujer, excepcional, de 73 años; en la publicada por Hattori y cols. (76), la más extensa, ocho pacientes varones entre 36 y 75 años de edad (media 71,7 años), de los cuales solamente uno se había tratado con penicilina, siendo la antigüedad más prolongada desde la sintomatología inicial de 32 años: entre los signos y síntomas que presentaban estos pacientes (76-Tabla 1: Clinical features of 8 male patients with tabes dorsalis) no se hace referencia alguna a la anacusia, pero sí a los hallazgos, en su caso, de pupila de "Argyll-Robertson"; uno de ellos presentaba retención urinaria, la capacidad máxima media fue de 561 cc y el primer deseo miccional con volumen medio de 350 cc., reseñando los autores que la tabes dorsal era una enfermedad frecuente antes de la era antibiótica, e incluso con posterioridad a la penicilina cuando los tratamientos habían sido inadecuados, siendo las disfunciones miccionales muy comunes en estos casos.

Quizá un paciente similar a estos fue a quien reconocieron los doctores L'Oliveira y Dopoude. Ellos relacionaron todos los signos y síntomas con una misma enfermedad que omitieron nombrar etiológicamente. Desconocemos cómo fue tratada la "perlesía", si Goya recuperó la micción espontáneamente, si precisó en adelante presionar externamente la zona hipogástrica para evacuar la vejiga o tuvo que ser sondado. Respecto al "tumor voluminoso al periné", habría que revisar la obra de Naval que toca éste asunto, o considerar, igualmente con las debidas reservas, que pudiera tratarse el bultoma de una "sifílide gomosa", un tumor redondeado, cutáneo o subcutáneo, que puede aparecer, único o múltiple, en cualquier punto de la economía, cuyo volumen puede alcanzar el "de un huevo de gallina", y el cual, alcanzada la fase de supuración y ulceración, cura dejando una cicatriz deprimida, radiada, de circunferencia frecuentemente pigmentada (77).

Goya falleció a las dos de la madrugada del día 16 de abril de 1828, en su domicilio de Burdeos, por entonces en la rue Fossés de L'Intendance, a consecuencia de un accidente cerebro-vascular (apoplejía) que le sobrevino el día 2. Quince días antes escribió la que sería su última carta dirigida a su hijo Javier (78), confesándole encontrase "en cama, un poco indispuesto", que no llegó a tiempo para acompañar a su padre en la agonía y muerte. Del cadáver de Goya, el artista don Francisco de la Torre tomó un dibujo a lápiz graso sobre piedra litográfica del que Gaulon obtuvo varias copias, de las cuales dos, una muy débil, se conservan en la Biblioteca Nacional. El profesor Esteve Botey obtuvo un calco y repasó el dibujo (79) el cual se reproduce como colofón (Figura 6). Goya recibió sepultura en el cementerio de Chartreuse, en la tumba de la familia Goicoechea donde reposaban los restos de su consuegro. Moratín, en París, moría el 21 de junio del mismo año.

\section{CONCLUSIÓN}

Son muchos, no obstante la extraordinaria bibliografía producida sobre la vida y obra de don Francisco de Goya, los interrogantes todavía no resueltos. Respecto a su pintura, la más popular y divulgada (80) es la ignota verdadera identidad del personaje femenino de las universalmente conocidas "Majas" (Gudiol 539 y 540. 97x190 y 95x188. Prado $n^{\circ}$ inv 742 y 741). Respecto a sus convicciones ideológicas y políticas, cuáles fueron éstas en realidad. Respecto a sus enfermedades, particularmente la minusvalía que le supuso su sordera absoluta, cuál fue su origen, cómo influyó en su obra pictórica y si también afectó, y en qué medida, a su personalidad y particular visión de su entorno y su propio ser.

Con carácter retrospectivo y con la información disponible, solamente es posible proponer cautelosa, y respetuosamente con las demás diferentes hipótesis o posibilidades diagnósticas fundamentadas en datos más o menos directos cuya veracidad absoluta no es, de acuerdo al método científico, aceptable como indudablemente fidedigno. Parece razonable, sin excluir otras, considerar que la enfermedad luética bien pudo afectar a Goya, condicionar su vida y su obra, y ser responsable del episodio mórbido con manifestaciones urológicas acontecido en Burdeos en 1825. Pero no obstante fueran ésta u otras las causas etiológicas, son las obras y la influencia del genial artista en la pintura española y universal quienes hablan por sí mismas de su extraordinario e intemporal legado. 


\section{BIBLIOGRAFÍA y LECTURAS RECOMENDADAS (*lectura de interés $y^{* *}$ lectura fundamental)}

*1. LAFUENTE FERRARI, E.; ANSÓN NAVARRO, A.: "Actitudes políticas en Goya". Goya, 250 años después. Ibercaja. Zaragoza. 11, 1996.

*2. GÓMIZ LEÓN, J.J.: "Goya 1746-1828. Su vida y sus obras, familia y amistades; circunstancias de su tiempo y semblanzas de los personajes más relevantes". Madrid, 391, 2006.

**3. CANELLAS LÓPEZ, A.: "Diplomatario de Francisco de Goya". Institución Fernando el CatólicoC.S.I.C. Zaragoza. documento $\mathrm{n}^{\circ}$ 267., pp.: 385386, 1982.

**4. DE SAMBRICIO, V.: "Tapices de Goya". Madrid, documento $\mathrm{n}^{\circ}$ 251., p.: CLVII, 1946.

5. Canellas, opus. cit. documento $\mathrm{n}^{\circ}$ CXLV., p.: 496.

6. DE SAMBRICIO, V.: opus. cit. documentos $\mathrm{n}^{\circ}$ 252., p.: CLVIII; $\mathrm{n}^{\circ} 253-255$., p.: CLIX y $\mathrm{n}^{\circ} 256$., p.: CLX.

*7. NÚÑEZ DE ARENAS, M.: "Manojo de noticias. La suerte de Goya en Francia". Bulletin Hispanique, LII, 3. Bordeaux, 229, 1950.

8. Canellas, opus. cit, documento $\mathrm{n}^{\circ}$ CXLVI., p.: 496.

*9. FERNÁNDEZ DE MORATÍN, L.: "Obras póstumas". Madrid. 1867-1868.

10. Canellas, opus. cit, documento $\mathrm{n}^{\circ}$ CXLVII., p.: 497.

**11. "Epistolario de Moratín" Edición de René Andioc. Castalia. Madrid 1973. documento ${ }^{\circ} 302$., p.: 586.

12. Canellas, opus. cit, documentos $n^{\circ}$ CXLVIII-CLI., pp.: 497-498.

13. Canellas, opus. cit, documento $\mathrm{n}^{\circ}$ 268., p.: 386.

**14. FAUQUÉ ZÚÑIGA, J.; VILLANUEVA ETCHEVERRÍA, R.: "Goya y Burdeos, 1824-1828”. Zaragoza, 218, 1982.

**15. CRUZ VALDOVINOS, J.M.: "La partición de bienes entre Francisco y Javier Goya a la muerte de Josefa Bayeu y otras cuestiones". Goya: nuevas visiones, Madrid, 27: 133, 1987.

16. Canellas, opus. cit, documento $\mathrm{n}^{\circ} 269$., pp. : 386387.

*17. MERAT, M.: "Traité de la Colique métallique". Paris, 1814.

*18. RUIZ DE LUZURIAGA, I.: "Disertación médica sobre el cólico de Madrid". Madrid, 1796.

**19. RODRÍGUEZ TORRES, Ma.T.: "Goya, Saturno y el Saturnismo. Su enfermedad”. Madrid, 1993.

20. Gómiz, opus. cit., p.: 388.

21. Canellas, opus. cit, documento $\mathrm{n}^{\circ} 270$., pp.: 387388.

22. Canellas, opus. cit, documento $\mathrm{n}^{\mathrm{o}}$ 271., p.: 388 .

23. Canellas, opus. cit, documento ${ }^{\circ}$ CLVI., p.: 499.
**24. GUDIOL, J.: "Goya, 1746-1828. Biografía, estudio analítico y catálogo de sus pinturas".4 tomos. Ediciones Polígrafa, Barcelona, 1970.

25. Canellas, opus cit, documento $\mathrm{n}^{\circ}$ 257., p.: 379.

*26. TELLO, J.: "Dos goyas poco conocidos". Boletín de la Sociedad Española de Excursiones, 36: 66, 1928.

*27. BATICLE, J.: "Francisco de Goya". Madrid, 337, 2204.

*28. MATHERON, L.: "Goya". Paris, 1858.

*29. YRIARTE, CH.: "Goya". Paris, 1867.

*30. Archivo General de Palacio, caja 606/12

31. Canellas, opus. cit, documento $n^{\circ}$ CLX., p.: 501

32. Canellas, opus. cit, documento $\mathrm{n}^{\circ}$ CLXIII., pp.: 502-503.

33. Canellas, opus. cit, documento $\mathrm{n}^{\circ}$ CLXV., pp.: 503-504.

34. Canellas, opus. cit, documento $\mathrm{n}^{\circ}$ CLXI., pp.: 501-502.

35. MATA, P.: "Tratado de Medicina y Cirugía Legal, seguido de un compendio de Toxicología. 2 tomos". $4^{\text {a }}$ Edición, ( $1^{\text {a }}$ de 1844). Tomo I. Madrid. 1866., p.: 110 y s.s.

36. Andioc, opus. cit, documentos $n^{\circ} 336$ y 338., pp.: 627 y 630.

*37. ROYO VILLANOVA, R.: "Goya y la Medicina”. Revista Universidad. Zaragoza, 1927.

38. Canellas, opus. cit, documento $\mathrm{n}^{\circ}$ LXVII., p.: 453.

39. Canellas, opus. cit, documento $\mathrm{n}^{\circ}$ LXVIII., p.: 454.

40. Canellas, opus. cit, documento ${ }^{\circ}$ LXIX., p.: 455.

41. Canellas, opus. cit, documento $\mathrm{n}^{\circ} \mathrm{LXX}$., pp.: 4556.

42. Canellas, opus. cit, documento $\mathrm{n}^{\circ} 185$., p.: 313.

43. Canellas, opus. cit, documento $\mathrm{n}^{\circ}$ LXVI., p.: 453.

*44. ZAPATER Y GÓMEZ, F.: "Goya: Noticias Biográficas”. Zaragoza, 1868.

45. Rodríguez Torres, opus. cit., nota 59., p.: 28.

**46. GARCÍA CUERPO, E.; LOVACO CASTELLANO, F.; SÁNCHEZ ENCINAS, M.: "La Urología Española en la Ilustración". Historia Biográfica y Bibliográfica de la Urología Española, Edición don Emilio Maganto Pavón. Oficina de Historia de la Asociación Española de Urología, Madrid, Capítulo III, 127, 2000.

**47. OTERO TEJERO, I.: "La Urología en la Ilustración". Tesis Doctoral. Facultad de Medicina de la Universidad de Alcalá de Henares, Madrid, 1990.

*48. MAGANTO PAVÓN, E.: "Doscientos años de la publicación del libro de Juan Naval: Tratamiento medico-quirúrgico de las enfermedades de las vías de la orina, 1799". LXIV Congreso Nacional de Urología, Zaragoza, Mayo, 1999.

**49. VALLÉS VARELA, H.: "Goya, su sordera y su tiempo". Acta Otorrinolaringol. Esp., 56: 122, 2005. 
*50. RAMAZZINI, B.: "De morbis artificium diatriba". Pádua, 1713.

*51. MITJAVILA Y FISONÉLL, VICENTE.: "De los daños que causan en el cuerpo humano las preparaciones del plomo". Barcelona, 1791.

*52. Dictionnaire Portafit de Santé. Paris. 1760.

*53. GÓMIZ LEÓN, J.J.: “ Cádiz y Goya, 1793, 1796 y 1797". Madrid, En prensa, 2006.

*54. CURBO SEMMEDO, J.: "Secretos médicos y Chirúrgicos”. Juan de Zúñiga Impresor, Madrid, 1725.

55. Mata, opus. cit: "De las cuestiones a que dan lugar los delitos contra la honestidad", pp.: 359-363.

56. Mata, opus. cit: "Declarar si la enfermedad que uno de los cónyuges o los dos padecen en sus órganos genitales u otras partes, prueba concúbito con otra persona infecta, o si puede ser reproducida de otra antigua, o espontánea"., pp.: 363-365.

57. Mata, opus. cit: "Si la afección que el cónyuge padece pertenece a los síntomas primarios, secundarios o terciarios del mal venéreo"., pp.: 365-369.

58. Mata, opus. cit: “¿Puede el mal venéreo desarrollarse como expresión de afecciones antiguas o espontáneamente?, pp.: 369-377.

59. Mata, opus. cit: “¿Es posible distinguir una afección sifilítica de la que no lo es?", pp.: 378-398.

**60. ANSÓN NAVARRO, A.: “Goya y Aragón”. Colección Mariano de Pano y Ruata, Caja de Ahorros de la Inmaculada de Aragón, Zaragoza, 24, 1995.

*61. DE TORRES VILLARROEL, D.: "Los desahuciados del mundo y de la gloria; deshauciado cuarto: el gálico". Edición de don Manuel. Ma . Pérez. Editora Nacional, Madrid, 133, 1979.

*62. ROUSSEAU, J.J.: "Las Confesiones; parte II, libro VII". Edición de don Juan del Agua, EspasaCalpe, Madrid, 272, 1983.

*63. FERNÁNDEZ DE MORATÍN, L.: "Viaje de Italia; cuaderno III: Roma y Nápoles”. Ediciones Laertes, Barcelona, 70, 1988.

**64. FERNÁNDEZ DE MORATÍN, N.: "Arte de las putas". Madrid, Edición de cincuenta ejemplares por don Emilio Cotarelo, 95 páginas en $8^{\circ}, 1898$.

**65. FERNÁNDEZ DE MORATÍN, N.: “Arte de las putas". Edición de don Manuel Fernández Nieto. Ediciones Siro. Madrid, notas 28 y 29., p.: 49, 1977.

*66. Archivo Histórico Nacional. Inquisición, Legajo
4428, número 30, folio 3v. y 4r.

*67. Archivo Histórico Nacional. Inquisición. Libro 1319, folio 212v. Índice de 1790 y Suplemento de 1805 .

*68. Archivo Histórico Nacional. Inquisición. Legajo 4449, número 8.

*69. SÁNCHEZ DE RIVERA, D.: "La enfermedad de Goya”. Revista Española de Arte, 22, 1934-35.

*70. BORS, E.; COMARR, A.E.: "Sensory Neuron Lesions" Neurological Urology, Karger Chapter, 6: 195,1971

**71. MORRISON, J.; STEERS, W.D.; BRADING, A. y cols.: "Neurophysiology and Neuropharmacology" Abrams,P; Cardozo,L; Khoury,S y Wein,A.: "Incontinence: Second International Consultation on Incontinence". Plymbridge Distributors Ltd. Plymouth, pp.: 89-90., tabla 2., referencias.: 6, 18, 19 y $28,2002$.

**72. MONLLOR, J.; MARTÍN, C.: “Conceptos actuales en anatomía, fisiología y farmacología del tracto urinario inferior" Salinas Casado, J; Romero Maroto, J.: "Urodinámica Clínica”. Jarpyo Editores. Madrid. Capítulo 1., p.: 24, referencia 13, 1995.

**73. VELA NAVARRETE, R.: "El riñón dilatado". Masson, S.A. Barcelona, 7: 136, 2001.

**74. TSE, W.M.; STONE, A.: "Neuropathic bladder dysfunction from tabes dorsalis" Coros, J; Schick, E.: "Textbook of the Neurogenic Bladder". R.Bonnett Pub M.D. Chapter, 19: 231, 2004.

**75. GARBER, S.J.; CHRISTMAS, T.J.; RICKARDS, D.: "Voiding dysfunction due to neurosyphilis". Br. J. Urol., 66: 19, 1990.

**76. HATTORI, T.; YASUDA, K.; KITA, K. y cols.: "Disorders of micturition in tabes dorsalis". Br. J. Urol., 65: 497, 1990.

*77. AUDRY, C.; DURAND, M.; NICOLÁS, J.: "Tratamiento de las enfermedades cutáneas y venéreas". Biblioteca de Terapéutica Gilbert y Carnot, 1920.

78. Canellas, opus. cit, documento $\mathrm{n}^{\mathrm{o}} 281$., p.: 395.

*79. ESTEVE BOTEY, F.: "Francisco de Goya y Lucientes, intérprete genial de una época". Barcelona, 1944.

**80. GÓMIZ LEÓN, J.J.; LA PARRA LÓPEZ, E.: “La Corte de Carlos IV". Centro de Estudios Políticos y Constitucionales. Madrid, 91: 222, 2006. 